\title{
Force and Temperature Conditions of Face Milling with Varying Chip Quotient as a Function of Angle of Rotation
}

\author{
János Kundrákㄹ, Zoltán Pálmai ${ }^{1}$, Bernhard Karpuschewski², Csaba Felhő ${ }^{1}$, Tamás Makkai ${ }^{1}$, Dmytro Borysenko ${ }^{3}$ \\ ${ }^{1}$ Institute of Manufacturing Science, University of Miskolc. Egyetemváros, 3515 Miskolc. Hungary. E-mail: ja- \\ nos.kundrak@uni-miskolc.hu, csaba.felho@uni-miskolc.hu, tamas.makkai@uni-miskolc.hu \\ ${ }^{2}$ Leibniz-Institut für Werkstofforientierte Technologien - IWT. 3 Badgartener Str., 28359 Bremen. Germany. E- \\ mail: karpuschewski@iwt-bremen.de \\ ${ }^{3}$ Institute of Manufacturing Technology and Quality Management, Otto von Guericke University Magdeburg, 2 \\ Universitätsplatz, 39106 Magdeburg, Germany. E-mail: dmytro.borysenko@ovgu.de
}

Increasing the efficiency of cutting operations while fulfilling the required (expected) quality of the parts constantly requires a thorough knowledge of the chip removal process. This is especially justified in the case of deviations from the usual (traditional) technological conditions or cutting data, both in terms of cutting theory and technique. This paper summarizes some of the results of a study of cutting force and cutting temperature in face milling. The technological analysis of face milling was performed by FEM simulation, which was compared and validated by measuring the cutting force. The chip removal of C45 rolled steel as a function of tool rotation was studied with two different depths of cut $a_{p}$ and feed rate $f_{z}$ so that at a constant nominal $A_{c}$ cross section the ratios $a_{p} / f_{z}$ were 0.1 and 10 . The effect of the change of the cross-section and chip ratio is shown.

Keywords: Face Milling, Cutting Force, Cutting Temperature

\section{Introduction}

The study of the mechanical and thermal processes of cutting technology has long been intertwined. This is also true for cutting performed with a rotary tool, as shown in Salomon's much-cited article [1]. He has already presented the measurement of cutting force and cutting temperature together during milling. These two characteristics of machining, force and temperature, have been the subject of intensive research ever since. As a typical example, among the newest investigation results, the mechanistic model by Shalabi et al. [2] can be mentioned for the case of precision machining where the depth of cut is made considerably smaller than the tool nose radius. It is especially important to know the conditions of chip removal when cutting difficult-to-machine materials with special compositions. Geng et al. [3] studied the machinability of a nickel-based superalloy by calculating and measuring the cutting force. The cutting force for milling this extremely difficult-to-machine material was determined with ABAQUS FEM software and the results were verified by force measurements. This made it possible to determine the optimal technology. Fan et al. [4] studied the cutting force for the industrially important Ti-6Al-4V alloy. Kecik et al. [5] rated the stability of the process in the machining of $\mathrm{Ni}$ superalloys by measuring the cutting force, and Huan et al. [6] measured the cutting force in the milling of Ti-matrix composites. Machining of special materials also requires the development of measurement methods. For the machining of aluminum alloys used in aviation, a 4-Component-High-Speed-Rotating-Cutting-Force-Dynometer was developed and used by Klocke et al. [7]. Knowledge of cutting forces is particularly important during machining non-metallic composite materials, such as carbon fiber reinforced plastics (CFRPs), which are becoming more widespread. Henerichs et al. [8] studied the effect of tool geometry and fiber orientation in machining by measuring the cutting force. The machining of biomedical Co-Mo-Mo alloys is a little studied field so far in the machining of special materials. Ahearne and Baron [9] performed a full factorial orthogonal cutting experiment. The constants of the Kienzle formula were established, with which the macro-mechanical modeling of more complex machining was established for this special material. A relatively new technology is turnmilling, in which the cutting force was investigated using a predictive analytical model by Karaguzela et al. [10]. For complex surfaces, Niederwestberg and Denkena [11] have extended the modeling of the cutting process to arbitrary milling operations in which milling is performed with a rotating tool. The new way of modeling made it possible to consider all the relevant technological parameters. Cui et al. [12] studied the cutting force in ultra-high speed milling. Abaqus/explicit FEM software was used for modeling. In particular, the complex processes in the tool tip environment require in-depth studies, which was investigated 
by Fernández-Abia et al. [13] in the high-speed turning of austenitic stainless steel. A geometrically similar problem was addressed by Ge et al. [14] for a threeedge tool, and by Aydin and Köklü [15], who modeled the cutting forces in ball-end milling.

One of the peculiarities of cutting is that difficult problems can arise even with the technology used in practice. This has been addressed by Zheng et al. [16] in face milling with cutter runout. The ongoing extensive cutting force studies promise answers to many problems. This is especially true for intermittent cutting like milling. More and more studies are appearing on calculating the cutting forces arising during milling [17]. Rubeo and Schmitz [18] used an empirical technological function to describe the dependence of the cutting force coefficients on process parameters such as feed per tooth, spindle speed, and radial immersion in milling. By examining the average and instantaneous forces they were able to separate the stable and unstable ranges of the process. From the cutting data at high feed machining, our research group studied the force change depending on the chip cross section [20] and the cutting speed [21], which increases productivity by increasing the feed rate [19]. It has also been found that by increasing the feed with a constant chip cross section, the cutting force decreases [22]. The relationship between cutting force and feed in face milling of steel has already been studied by Korkut and Donertas [23]. Karpuschewski and Batt [24] used the so-called inverse cutting technology and measured the cutting forces during milling with stepped cuts. With this, they were able to create a favorable cutting process. Borysenko et al. [25] showed that the deformation of the material is less in inverse cutting than in conventional cutting, resulting in a significant reduction in cutting force and more favorable workpiece surface integrity. Reducing machining energy requirements requires process forecasting. Rief et al. [26] successfully used specific cutting force for a holistic analysis of specific energy consumption. On the basis of this brief review of the literature, it can be concluded that the study of cutting force has long been, and still is, the focus of interest for technology developers.

This paper describes studies aimed at the complex analysis of machining energy demand and cutting temperature using FEM in milling. It has been shown that by validating the FEM analysis by force measurements, the thermal processes of chip removal can be reliably studied without labor-intensive and costly measurement of temperature conditions.

\section{2The performed investigations and their conditions}

\subsection{Investigation method}

The process of chip removal by face milling was analyzed using the finite element method (FEM). The change in cutting forces was also examined by cutting experiments and the force measurement data were compared with the FEM results, thus the results were validated at the same time (Fig. 1). This was done based on the specific cutting force values. As a result of the FEM tests, the change of the cutting temperature was also shown as a function of the rotation of the milling tool.

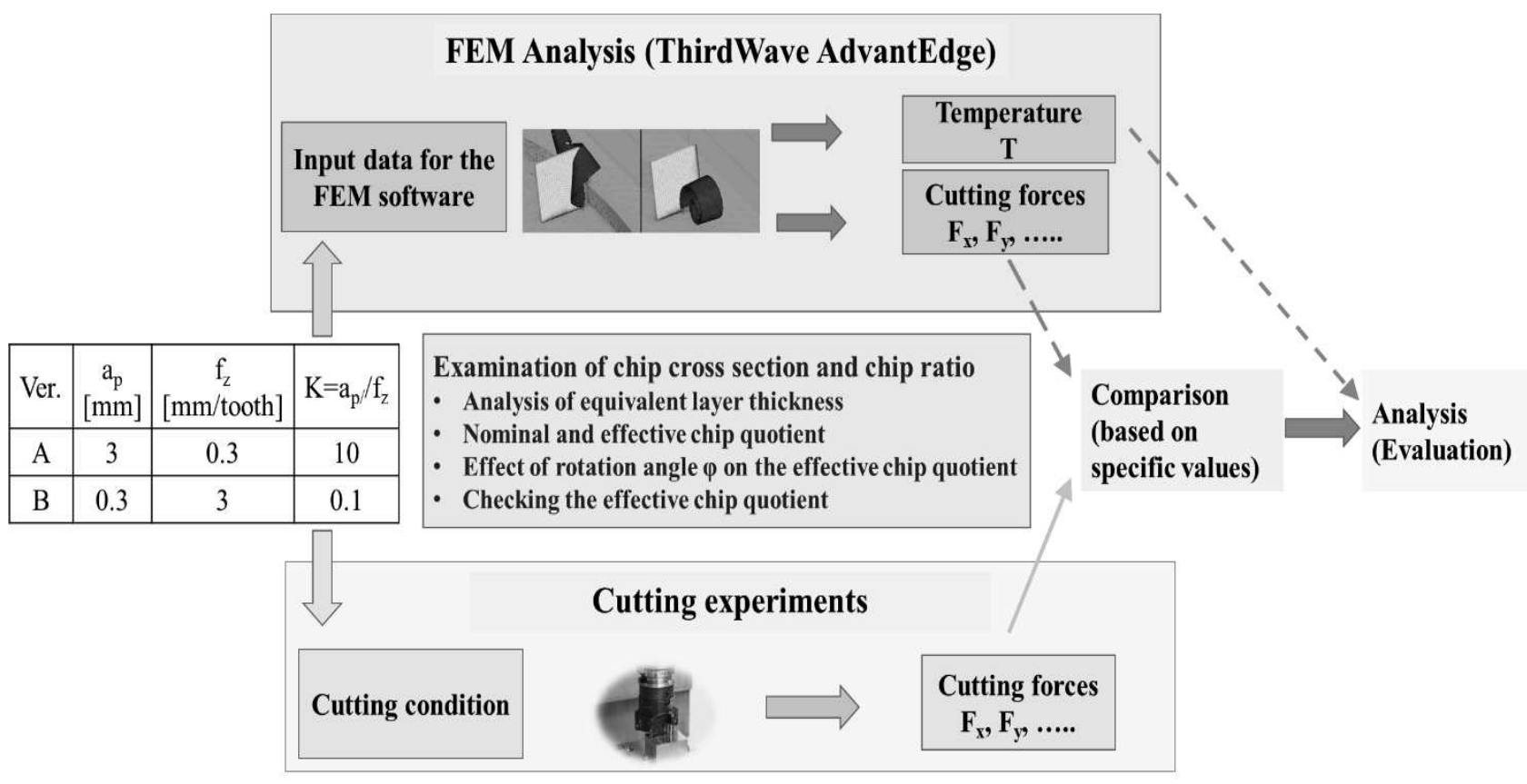

Fig. 1 Investigation steps 
Since machining with a rotary tool is characterized by intermittent chip separation and chips of variable cross-section, the current technological process was examined as a function of four characteristics. These are the angular rotation of the cutter $\varphi$, the nominal layer thickness $h \cdot \sin \varphi$, the equivalent layer thickness $\mathrm{h}_{\mathrm{eq}}$ and the chip quotient $\mathrm{K}$. The tests were performed taking into account an equivalent layer thickness $\left(\mathrm{h}_{\mathrm{eq}}\right)$ that is the quotient of the actual (approximate) cross section $\left(A_{c}(\varphi)=a_{p} \cdot f_{z} \cdot \sin \varphi\right)$ corresponding to the angular rotation of the milling tool $\varphi$ and the cutting edge length $l_{c}(\varphi)[27]$. As the $h_{\text {eq }}$ equivalent layer thickness is not sufficient for the satisfactory characterization of the technological variants occurring in practice, it is justified to introduce the chip quotient $\mathrm{K}=\mathrm{a}_{\mathrm{p}} / \mathrm{f}_{\mathrm{z}}$ [24]. In milling, the actual chip ratio also varies as a function of the angle of rotation $\varphi$, so it is expedient to distinguish from the nominal chip quotient $\mathrm{K}=\mathrm{a}_{\mathrm{p}} / \mathrm{f}_{\mathrm{z}}$ the effective chip quotient $a_{p} /\left(f_{z} \cdot \sin \varphi\right)$, which is denoted as $\mathrm{K}_{\text {eff; }}$, the value of which can vary greatly during the rotation of the cutter [27]. The characteristic (distinguished) points of the angle of rotation of the cutter are shown in Fig. 2, where point "1" is the place of entry into the cut, point " 2 " is the place of exit from the cut.

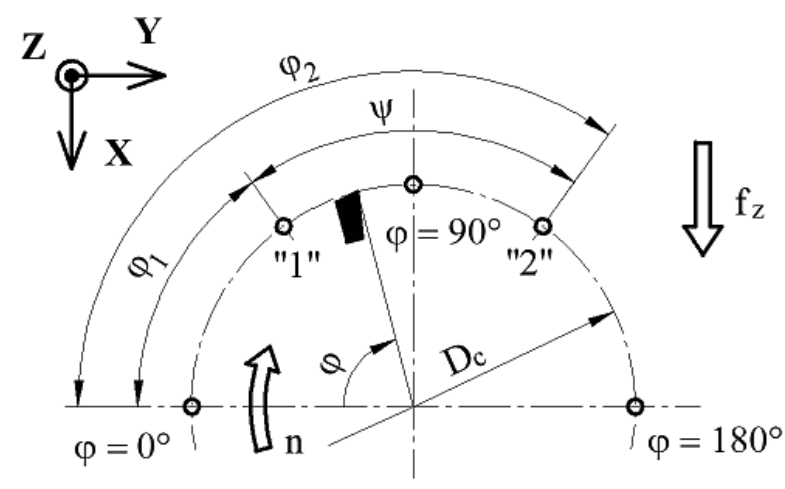

Fig. 2 Characteristic points of the angle of rotation of the cutter

\subsection{FEM simulation tools}

The FEM simulations were performed with the ThirdWave AdvantEdge Finite Element software, which is a dedicated FEM modeling system for such cutting processes as turning, milling, or drilling. It can be used to analyze the chip formation process, temperature, cutting forces, etc.

The input parameters for the simulation are introduced in the following. Our intention was to provide parameters as close to the real cutting experiments as possible, within the given boundary conditions.

Workpiece: material: C45 (200 Bhn); length: 5 mm; height: $30 \mathrm{~mm}$; width: $70 \mathrm{~mm}$.

Tool: $\mathrm{D}_{\mathrm{c}}=120 \mathrm{~mm}$; insert shape: $\mathrm{S}$ (square); nose radius: $0.8 \mathrm{~mm}$; insert width: $0.5 \mathrm{~mm}$; radial rake angle: $0^{\circ}$; axial rake angle: $12^{\circ}$; lead angle: $0^{\circ}$; relief angle: $15^{\circ}$; number of teeth: 1; edge radius: $0.015 \mathrm{~mm}$; material:

\section{Carbide-General.}

Process parameters: spindle speed: 530 RPM; feed per tooth: $0.3,3 \mathrm{~mm}$; depth of cut: $3,0.3 \mathrm{~mm}$; angle of rotation: $75^{\circ}$; dry cutting; initial temperature: $20^{\circ} \mathrm{C}$.

Symmetrical face milling was modeled. The mesh parameters were adjusted to be fine enough at the vicinity of the cutting edge while keeping running time under control. Thus, the minimum element size in the tool was set at $0.065 \mathrm{~mm}$, while in the workpiece and in the chip it was set at $0.005 \mathrm{~mm}$. The workpiece and tool material were selected from the standard material library of the software. Among the technological parameters, the values of the depth of cut and the feed per tooth were varied and the other parameters were constant. The cutting data were selected in such a way that material removal took place at significantly different chip ratios. Accordingly, we worked with a $3 \mathrm{~mm}$ depth of cut at a feed per tooth of $0.3 \mathrm{~mm}$ and with a depth of cut of $0.3 \mathrm{~mm}$ at a feed of $3 \mathrm{~mm}$. Thus, the chip ratios examined were as follows: $K_{1}=10$ (A) and $\mathrm{K}_{2}=0.1(\mathrm{~B})$.

\subsection{Condition of cutting experiments and force mea- suring system}

The experiments were performed on a Heller FT2000 vertical machining center. During cutting, a Garant XOEW 120508 PDER-W insert was used, which was clamped in a custom-made, expediently designed face milling head [25]. A single insert was placed in the tool, the reason being that the chip separation process could be examined independently of the interaction of several edges. The geometry of the experimental tool was the same as the geometry of the tool used in the finite element simulations:

- tool diameter: $\mathrm{D}_{\mathrm{c}}=120 \mathrm{~mm}$

- major cutting edge angle: $x_{\mathrm{r}}=90^{\circ}$

- nose radius: $\mathrm{r}_{\mathrm{s}}=0,8 \mathrm{~mm}$

- cutting edge radius: $\mathrm{r}_{\beta}=0,015 \mathrm{~mm}$

- radial rake angle: $\gamma_{\mathrm{f}}=0^{\circ}$

- axial rake angle: $\gamma_{\mathrm{p}}=12^{\circ}$

In the experiments, $\mathrm{C} 45$ rolled C-steel was used as the workpiece. Its hardness was about HB200. The cutting parameters were also the same as those used in the finite element simulation. The cutting speed $\left(\mathrm{v}_{\mathrm{c}}\right)$ was $200 \mathrm{~m} / \mathrm{min}$, the spindle speed was set accordingly to $\mathrm{n}=530 \mathrm{1} / \mathrm{min}$. Based on the expedient design of the workpiece, the working width $\left(\mathrm{b}_{\mathrm{w}}\right)$ was $70 \mathrm{~mm}$. The depth of cut $\left(a_{p}\right)$ was set to two values: $0.3 ; 3 \mathrm{~mm}$, the feed per tooth $\left(\mathrm{f}_{\mathrm{z}}\right)$ was also of two values: $0.3 ; 3$ $\mathrm{mm}$, but so that the nominal undeformed chip crosssection $\left(A_{c}=a_{p} \cdot f_{z}\right)$ was a constant value of $0.9 \mathrm{~mm}^{2}$.

A Kistler 9255B three-component dynamometer was used for force measurements. Three 5011 type charge amplifiers were connected to this (also made by Kistler). The measured signal was then transmitted 
to the data recording and processing laptop via a $\mathrm{Na}$ tional Instruments USB 6212 data acquisition unit. The measurement software used on the laptop was written in the LabView programming language.

\section{Comparative study of cutting forces (spe- cific values)}

The results of the FEM run (example given in Fig. 3) were compared with the results obtained during the cutting experiments. It was examined, how well the values obtained with FEM follow the values obtained in the experiments as a function of the rotation of the tool and whether there is a difference from the values obtained at different chip ratios.

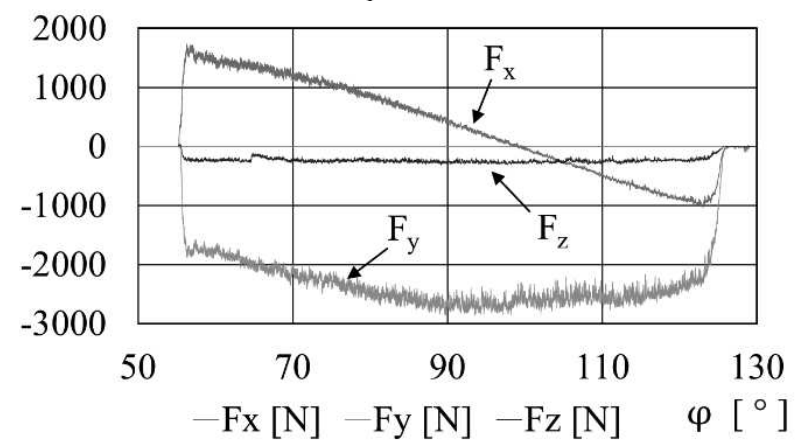

a) Experimental setup $A: a_{p}=3 \mathrm{~mm} ; f_{z}=0,3 \mathrm{~mm} ; K=10$

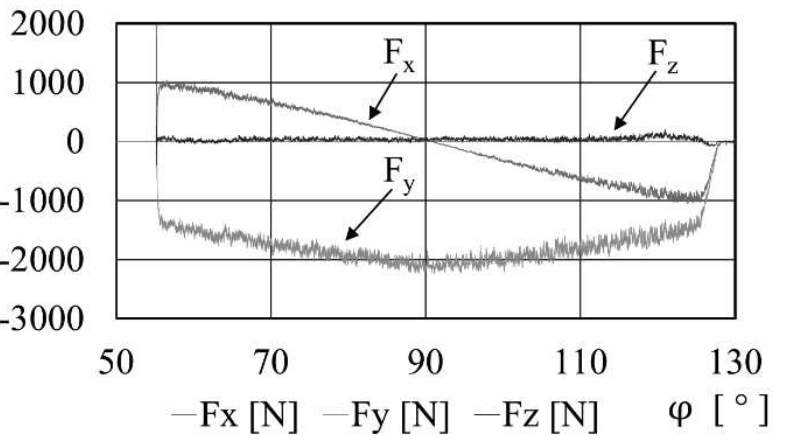

b) Experimental setup $B: a_{p}=0.3 \mathrm{~mm} ; f_{z}=3 \mathrm{~mm} ; K=0.1$

Fig. 3 FEM run results

The FEM calculations were analyzed and compared by determining the cutting force $\mathrm{F}_{\mathrm{xy}}\left(\mathrm{F}_{\mathrm{a}}\right)$ (active force) in the base plane of the tool in versions $A$ and $\mathrm{B}$ and the specific cutting force $\mathrm{k}_{\mathrm{xy}}$ calculated from it. The cutting force $F_{x y}$ was obtained as the resultant of $F_{x}$ and $F_{y}$ using the following relation:

$$
F_{x y}=\sqrt{F_{x}^{2}+F_{y}^{2}} \text {. }
$$

3.1 Comparison of $\mathrm{F}_{\mathrm{xy}}$ cutting force and $\mathrm{k}_{\mathrm{xy}}$ specific cutting force

In the axis of symmetry of the workpiece - where the angle of rotation of the cutter is $90^{\circ}$ - the data belonging to different milling positions were compared to the measured and calculated values (Figs. 2 and 3 ) - with respect to the standard deviation - by calculating with the mean value of the interval $\varphi=$ $90^{\circ} \pm 2^{\circ}$.The ratios of $\mathrm{F}_{\mathrm{xy}}(\varphi) / \mathrm{F}_{\mathrm{xy}}\left(\varphi=90^{\circ}\right)$ and $\mathrm{k}_{\mathrm{xy}}(\varphi) / \mathrm{k}_{\mathrm{xy}}\left(\varphi=90^{\circ}\right)$ were determined in this way, the values of which are thus equal to one at $\varphi=90^{\circ}$. Thus, both in the measurements and in the calculation of the FEM, a characteristic is obtained as a function of the angle $\varphi$; in case of the similarity of the two the results of the FEM calculations can be considered validated by the measurements. For the $\mathrm{F}_{\mathrm{xy}}$ cutting force component, this characteristic is shown in Fig. 4.

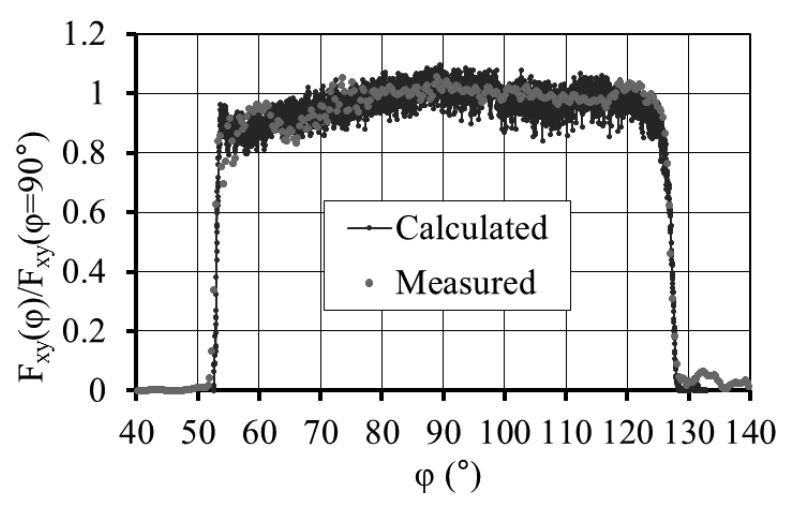

a) Version $A$

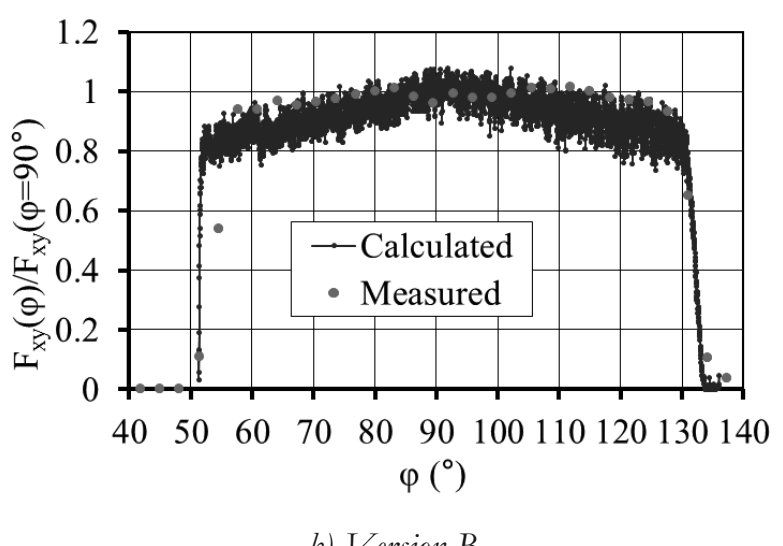

b) Version $B$

Fig. 4 Relative values of the force $F_{x y}$ according to the values measured and calculated at $\varphi=90^{\circ}$

A similar method was used to compare the measured and calculated values of $\mathrm{k}_{\mathrm{xy}}$ specific cutting force (Fig. 5).

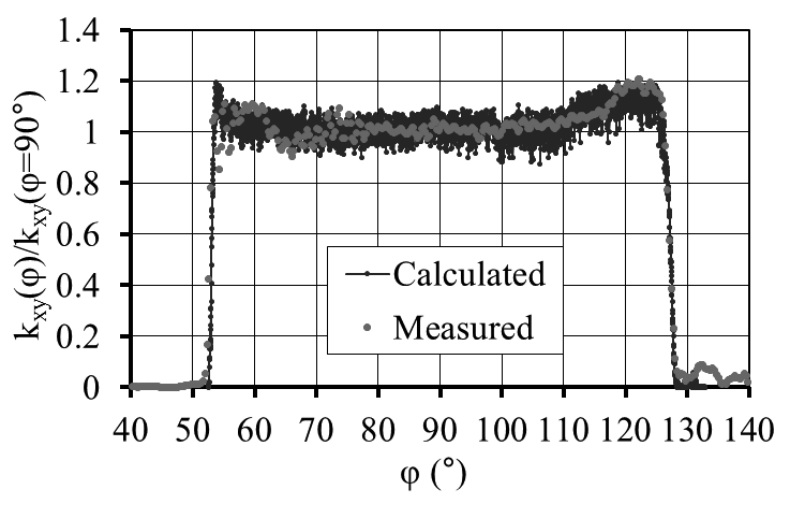

a) Version $A$ 


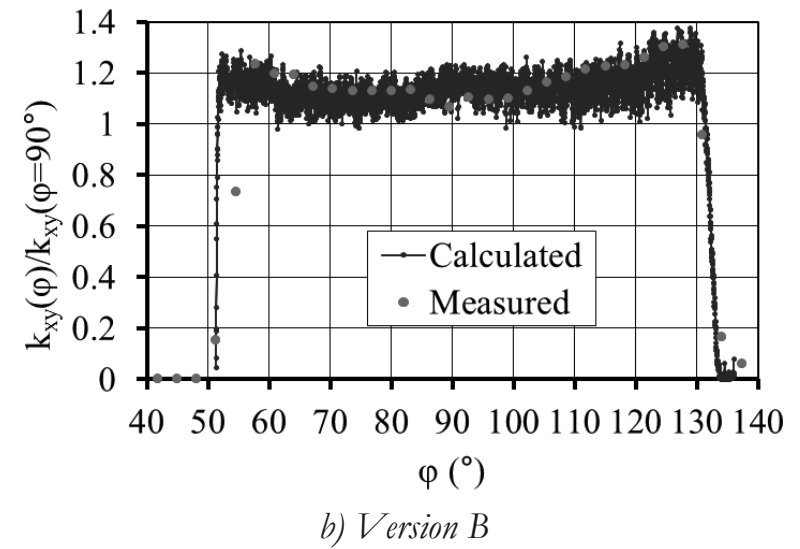

Fig. 5 Relative values of the specific cutting force kxy according to the values measured and calculated at $\varphi=90^{\circ}$

At the milling cutter angle position $\varphi$, the momentarily removed material cross section $A_{\varphi}$ is $A_{c}(\varphi)=a_{p} \cdot f_{z} \cdot \sin \varphi$. Here, in view of the large difference between the cutting speed and the feed rate, the difference between the real cycloid path of the tool edge and the circular arc assumed as an approximation is neglected. As a function of this actual material crosssection $A_{c}(\varphi)$, the characteristic curve of the ratios $\mathrm{F}_{\mathrm{xy}}(\varphi) / \mathrm{F}_{\mathrm{xy}}\left(\varphi=90^{\circ}\right)$ and $\mathrm{k}_{\mathrm{xy}}(\varphi) / \mathrm{k}_{\mathrm{xy}}\left(\varphi=90^{\circ}\right)$ develops specifically, which is shown in Fig. 6. The marks $\bullet$ and $\boldsymbol{\Delta} \mathrm{s}$ indicate the initial phase of cutting.
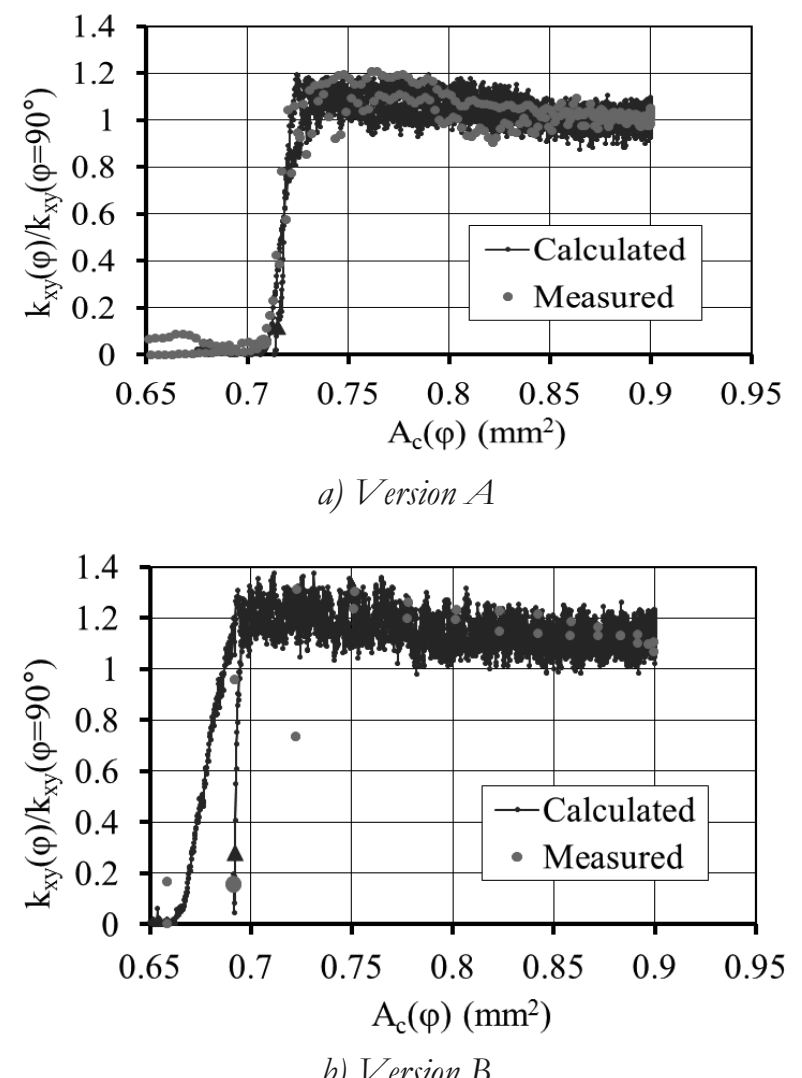

Fig. 6 Relative values of the specific cutting force $k_{x y}$ compared to the measured and calculated value at $\varphi=90^{\circ}$ as a function of the momentarily removed cross section $A_{c}(\varphi)$
Based on Fig. 6, it can be concluded that the force required to separate the material of cross section $A_{\varphi}$ is not exactly the same in the ascending and descending phases. This particular fact can be established for both the measured data and the FEM calculation results for both versions. The characteristic curves shown in Figures 4-6 can be considered as validating the FEM calculation results with force measurements.

\subsection{Scattering of the measured and calculated values}

When measuring the cutting force, it is not uncommon for the scattering of the results to be quite large due to the many factors influencing the process. It is noteworthy that the same is true for FEM results, suggesting an interesting analogy.

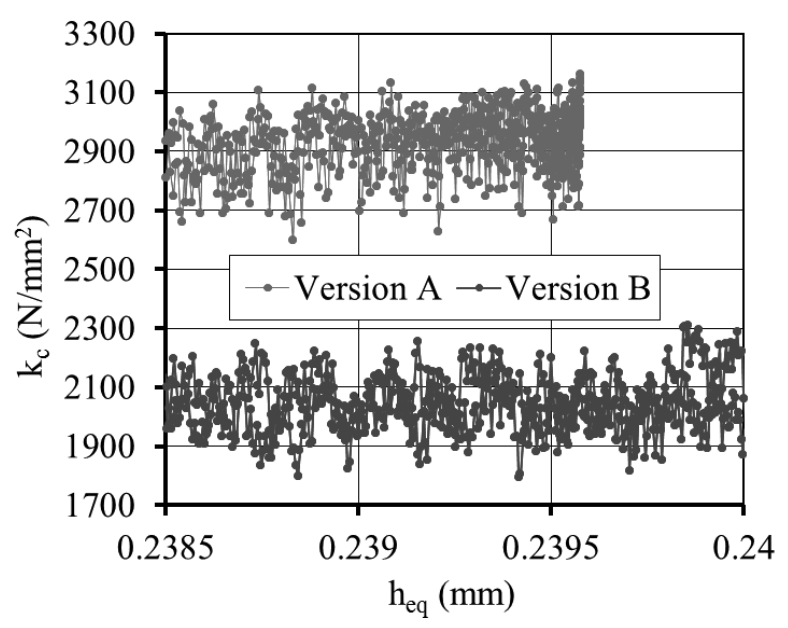

a) The scattering for Versions $A$ and $B$

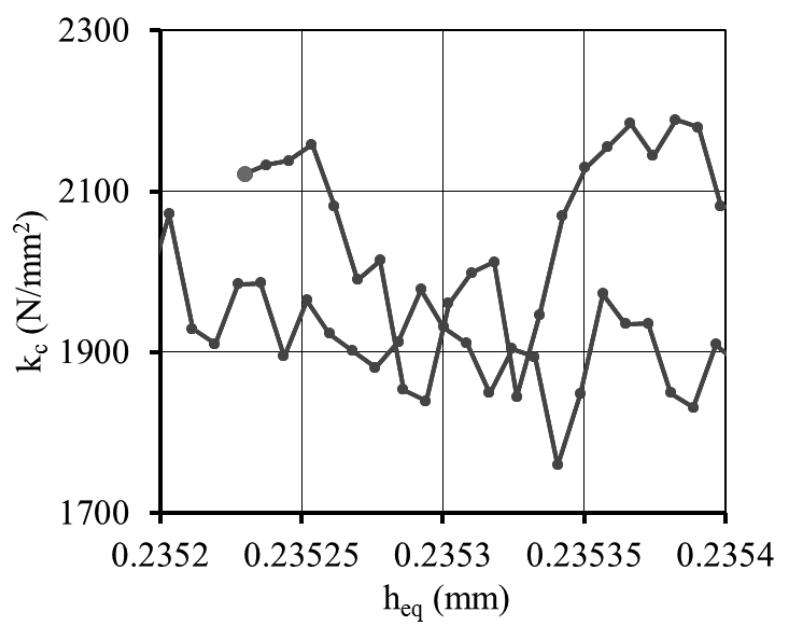

b) The $h_{\text {eq- }} k_{\text {c }}$ relationship, where the exit from the cut can also be seen

Fig. 7 The specific cutting force as a function of the equivalent thickness $h_{\text {eq }}$ of the deposited material layer, at different scales

(Version B, • shows the exit cutting)

Chip removal is characterized by large and rapidly changing deformation and quick, large temperature changes. As a result, opposite effects also occur, such 
as an increase in the forming strength, i.e., the forming hardness, due to the high deformation and the high deformation rate. At the same time, due to the rapid increase in temperature, thermal softening occurs. This may cause a chaotic phenomenon of deterministic instability known from nonlinear dynamics, which has already been modeled and verified by several researchers [28]. Thus, the reasons for the scattering of the measurement results are not limited to the possible instability of the measurement system, but can also be that the process itself causes a significant fluctuation in the measured data.

The FEM simulation can be characterized similarly. The constitutive equation describing the important properties of a plastically rapidly deformed material naturally includes the characteristic data that can be used in the calculations to consider the effect of deformation, deformation resistance, deformation rate, and thermal softening. The natural consequence of this is that the results are also scattered in the technological process simulated in this way.

The standard deviation of the data obtained by the FEM calculation is, of course, shown in the calculated time series, the specific manifestation of which is then shown in Fig. 7 as a function of the $h_{\text {eq }}$ equivalent thickness. The significant scattering of the specific cutting force can be seen here, as well as the characteristic of the equivalent layer thickness $h_{\mathrm{eq}}$ in diagram $\mathrm{a}$. This is manifested in the fact that $h_{e q}(\varphi)=A_{c}(\varphi) / l_{c}(\varphi)$, $l_{c}=a_{p}+f_{z} \cdot \sin x_{r} \cdot \sin \varphi+r_{\varepsilon} \cdot(\pi / 2-1), \quad$ if $\quad r_{\varepsilon} \leq a_{p}$ while $l_{c}=f_{z} \cdot \sin x_{r} \cdot \sin \varphi+r_{\varepsilon} \cdot \arccos \left(1-a_{p} / r_{\varepsilon}\right)$, if $r_{\varepsilon} \geq a_{p}$; and in these formulas the effect of $\sin \varphi$ has a clearly visible maximum; while at higher $h_{\mathrm{eq}}$ values there are no longer calculation results (Fig. 7a). Figure 7b shows a range of $h_{\text {eq }}$ values where exit from cutting is also visible.

\section{Temperature in chip root}

Like the specific cutting force, the cutting temperature is usually given by an empirical formula and a fractional power function as a function of the technological parameters $a_{p}, f_{z}$, etc. This does not apply to milling, as the calculation results shown in the following figures suggest. Figure 8 shows the temperature formed in the chip root as a function of the angle of rotation $\varphi$ of the cutter. The same is shown in Fig. 9 in specific value and in a narrower range. Here, the reference basis of the data for Version $B$ is the average calculated for the interval $\varphi=90^{\circ} \pm 2^{\circ}$, which is $\mathrm{T}_{\mathrm{o}}=717.9^{\circ} \mathrm{C}$.

In terms of variance, a characteristic difference can be established between the studied versions. For Version $\mathrm{B}$, the outliers appear to be larger, as shown in Fig. 9. This is even more striking in Fig. 10, where the temperature formed in the chip root is plotted as a function of the nominal chip thickness. Here it is clear that at $\mathrm{f}_{\mathrm{z}} \cdot \sin \varphi=3 \mathrm{~mm}$ the curve "reverses" and continues at somewhat higher temperature values. These facts also confirm that in addition to the commonly used parameters, the chip quotient should be used when examining the technological features of milling and evaluating the results.

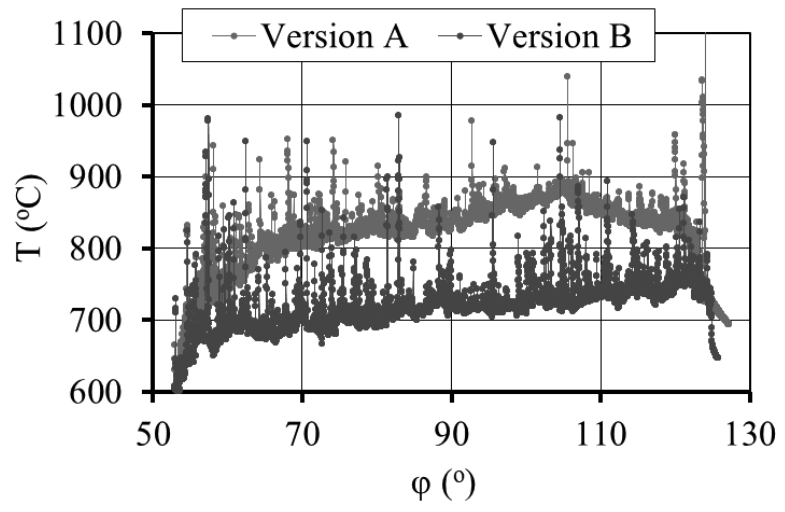

Fig. $\boldsymbol{8}$ Temperature in the chip root as a function of the angular position of the cutter $\varphi$

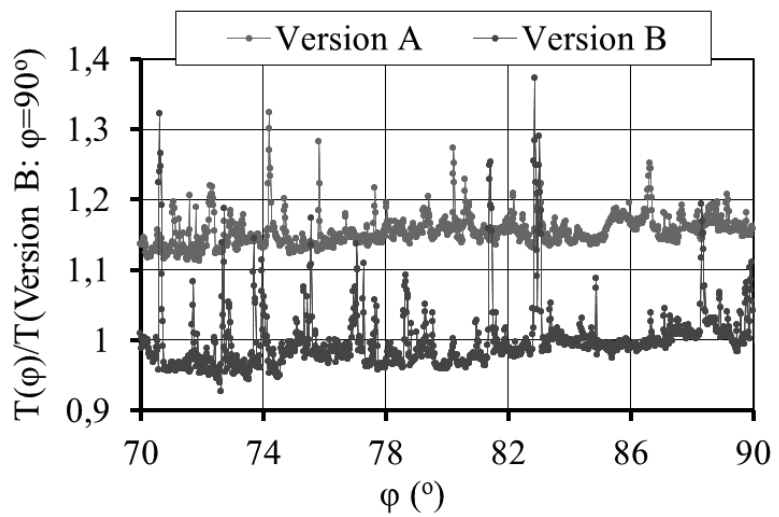

Fig. 9 Temperature relative to $\varphi=90^{\circ}$ as a function of cutter angle $\varphi$

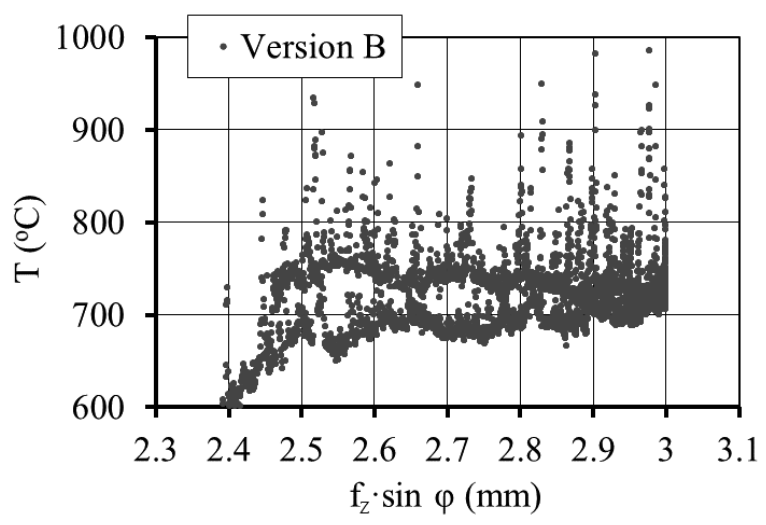

Fig. 10 Chip temperature as a function of the nominal thickness of the removed layer (version B).

A similar situation is observed when the temperature is examined as a function of the equivalent thickness (Fig. 11). It seems reasonable to assume that there is a strong correlation between the specific energy requirement of cutting and the temperature in 
the chip root. However, the FEM calculation results shown in Fig. 12 indicate that a characteristic difference can be seen for the two chip ratios. It is also interesting that the ratio of temperatures formed in versions $A$ and $B$ is significantly lower than the ratio of specific energy demand. This is presumably due to the fact that the heat dissipated during chip removal has a different distribution in the two cases.

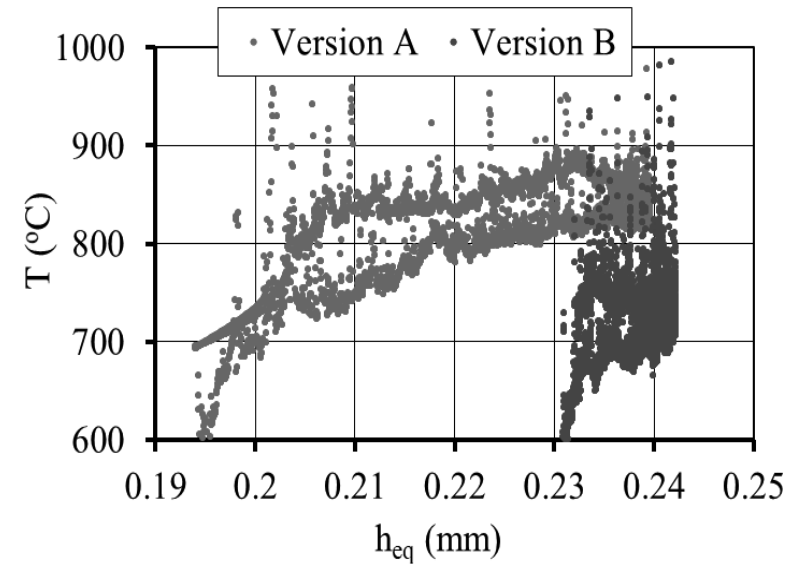

Fig. 11 Chip temperature as a function of the equivalent thickness of the removed layer $h_{\text {eq }}$

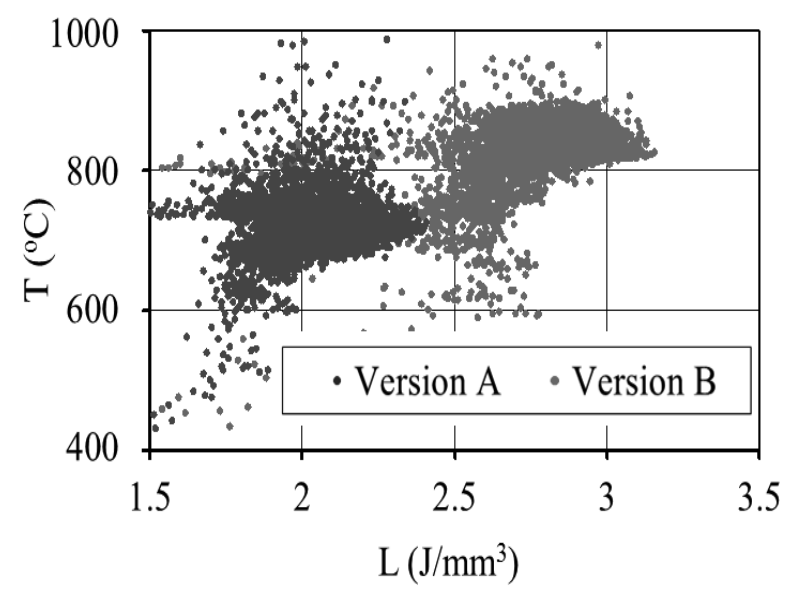

Fig. 12 The temperature of the chip root as a function of the specific energy required for chip removal

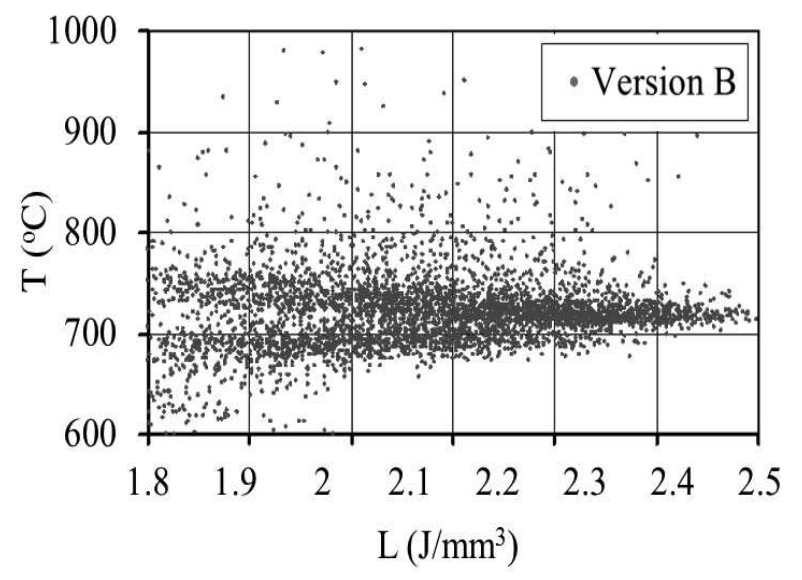

Fig. 13 Enlarged detail from Fig. 12 for Version B
It can also be stated that the variance of the calculation results is very large in both versions. Also noteworthy is the undoubted fact that the specific energy of the rotary cutter exceeding the value of $\varphi=90^{\circ}$ causes a different temperature rise in the chip root than in the range below $90^{\circ}$ (Fig. 13). Another important calculation result is that it is more energy-efficient if the operation takes place in the range $K<1$. This suggests that more energy is required to remove the same amount of material under non-free cutting conditions than in free cutting. In fact, the theory of nonfree cutting still needs to be developed in many respects. Of course, there are aspirations in this direction, as in the work of Shi and Wang [29], but further analyses are needed.

It is noteworthy that the rapid change in power demand is not of an alternating nature. This would make it probable that the phenomenon is a characteristic of mathematical simulation and not a characteristic of the technological process. Here, however, there are also points arising from the calculation on the ascending and descending sections of the smaller and larger waves. This makes it probable, for the time being without any evidence, that FEM here simulates a feature of chip removal characteristic of milling. For cutting under other cutting conditions, but with repeatedly increasing nominal undeformed chip thickness h, Csernák and Pálmai [30] concluded that in this case harmonics of the frequency of intermittent cutting can also be formed. This is noteworthy in milling because it can cause vibration excitation at a frequency that approaches one of the self-frequencies of the machining system, and this resonance can be notoriously harmful. This feature of milling needs to be further investigated.

\section{Summary}

The continuous development of material removal by cutting requires the examination of the most important characteristics, such as the cutting force. In this work we examined face milling, with emphasis on the shape of the removed chip cross section. The analysis was performed with ThirdWave AdvantEdge FEM software and by cutting experiments with $a_{p} / f_{z}=0.1$ and 10 ratios on C45 steel. It was found that in the case of rotary tools, the material removal is well characterized by the nominal layer thickness $\mathrm{h} \cdot \sin \varphi$, the equivalent layer thickness $\mathrm{h}_{\mathrm{eq}}$ and the chip quotient $a_{\mathrm{p}} / \mathrm{f}_{\mathrm{z}}$ in addition to the angular rotation of the cutter $\varphi$. When using the chip quotient $K=a_{p} / f_{z}$, it is also expedient to distinguish between the nominal value and the actual one, which is related to the position of the cutter $\varphi$. It was found that the chip quotient $\mathrm{K}$ is a good indicator of chip removal conditions, such as cutting force and temperature in the chip root. It is energetically favorable if the chip quotient is as small as possible $(K<1)$. 


\section{References}

[1] SALOMON, C. (1929). Schnittdruck- und Schneidtemperatur Erscheinungen an der Werkzeugschneide. In: Die Werkzengmaschine. Zeitschrift für Metallbearbeitung und Mascbinenbau, Vol. 33. No. 23., pp. 477-496.

[2] SHALABY, M.A., EL HAKIM, M.A., VELDHUIS, S.C., DOSBAEVA, G.K. (2017). An investigation into the behavior of the cutting forces in precision turning. In: The International Journal of Advanced Manufacturing Technology, Vol. 90, pp. 1605-1615.

[3] GENG, G., ZHANG, L., XIAO, M., DONG, X., CHEN, K. (2020). Finite element analysis and parameter optimization selection of high speed milling GH4169. In: Manufacturing Technology, Vol. 28, No. 3, pp. 300-306.

[4] FAN, Y., ZHENG, M., ZHANG, D., YANG, S., CHENG, M. (2014). Static and dynamic characteristic of cutting force when high-efficiency cutting Ti-6Al-4V. In: Key Engineering Materials, Vols. 589-590, pp. 122-128.

[5] KECIK, K., RUSINEK, R., WARMINSKI, J. (2011). Stability lobes analysis of nickel superalloys milling. In: International Journal of Bifurcation and Chaos, Vol. 21, No. 10, pp. 2943-2954.

[6] HUAN, H., XU, J., SU, J., FU, Y., GE, Y. (2014). Experimental study on milling of titanium matrix composites. In: Key Engineering $\mathrm{Ma}$ terials, Vols. 589-590, pp. 281-286.

[7] KLOCKE, F., ADAMS, O., AUERBACH, T., GIERLINGS, S., KAMPS, S., REKERS, S., VESELOVAC, D., ECKSTEIN, M., KIRCHHEIM, A., BLATTNER, M., THIEL, R., KOHLER, D. (2015). New concepts of force measurement systems for specific machining processes in aeronautic industry. In: CIRP Journal of Manufacturing Science and Technology, Vol. 9, pp. 31-38.

[8] HENERICHS, M., VOß, R., KUSTER, F., WEGENER, K. (2015). Machining of carbon fiber reinforced plastics: influence of tool geometry and fiber orientation on the machining forces. In: CIRP Journal of Manufacturing Science and Technology, Vol. 9, pp. 136-145.

[9] AHEARNE, E., BARON, S. (2017). Fundamental mechanisms in orthogonal cutting of medical grade cobalt chromium alloy (ASTM F75). In: CIRP Journal of Manufacturing Science and Technology, Vol. 19, pp. 1-6.

[10] KARAGUZEL, U., BAKKAL, M., BUDAK, E. (2017). Mechanical and thermal modeling of orthogonal turn-milling operation, In: Procedia CIRP, Vol. 58, pp. 287-292.

[11] NIEDERWESTBERG, D., DENKENA, B. (2014). Simulation of thermal and mechanical workpiece load. In: CIRP Journal of Manufacturing Science and Technology, Vol. 7, pp. 315-323.

[12] CUI, X., ZHAO, B., JIAO, F., ZHENG, J. (2016). Chip formation and its effects on cutting force, tool temperature, tool stress, and cutting edge wear in high- and ultra-high-speed milling. In: The International Journal of Advanced Manufacturing Technology, Vol. 83, pp. 55-65.

[13] FERNÁNDEZ-ABIA, A.I., BARREIRO, J., LÓPEZ DE LACALLE, L.N., MARTÍNEZPELLITERO, S. (2012). Behavior of austenitic stainless steels at high speed turning using specific force coefficients, In: The International Journal of Advanced Manufacturing Technology, Vol. 62, pp. 505-515.

[14] GE, G., BAOHAI, W., DINGHUA, Z., MING, L. (2013). Mechanistic identification of cutting force coefficients in bull-nose milling process, In: Chinese Journal of Aeronautics, Vol. 26, No. 3, pp. 823-830.

[15] AYDIN, M., KÖKLÜ, U. (2017). Identification and modeling of cutting forces in ball-end milling based on two different finite element models with Arbitrary Lagrangian Eulerian technique. In: The International Journal of Advanced Manufacturing Tecbnology, Vol. 92, pp. 1465-1480.

[16] ZHENG, H.Q., LI, X.P., WONG, Y.S., NEE, A.Y.C. (1999). Theoretical modelling and simulation of cutting forces in face milling with cutter runout. In: International Journal of Machine Tools \& Manufacture, Vol. 39, pp. 2003-2018.

[17] KOLAR, P., SULITKA, M., FOJTŮ, P., FALTA, J., ŠINDLER, J. (2016). Cutting force modelling with a combined influence of tool wear and tool geometry. In: Manufacturing Technology, Vol. 16, No. 3, pp. 524-531.

[18] RUBEO, M.A., SCHMITZ, T.L. (2016). Milling Force Modeling: A comparison of two approaches. In: Procedia Manufacturing, Vol. 5, pp. 90-105.

[19] KARPUSCHEWSKI, B., KUNDRÁK, J., EMMER, T., BORYSENKO, D. (2017). A new strategy in face milling - inverse cutting technology. In: Solid State Phenomena, Vol. 261, pp. 331-338.

[20] KUNDRÁK, J., MARKOPOULOS, A.P., MAKKAI, T., KARKALOS, N.E. (2019). Effect of edge geometry on cutting forces in 
face milling with different feed rates. In: Manufacturing Technology, Vol. 19, No. 6, pp. 984-992.

[21] KUNDRÁK, J., MARKOPOULOS, A.P., MAKKAI, T., DESZPOTH, I., NAGY, A. (2018). Analysis of the effect of feed on chip size ratio and cutting forces in face milling for various cutting speeds. In: Manufacturing Technology, Vol. 18, No. 3, pp. 431-438.

[22] KUNDRÁK, J., GYÁNI, K., FELHŐ, C., DESZPOTH, I. (2017). The effect of the shape of chip cross section on cutting force and roughness when increasing feed in face milling. In: Manufacturing Technology, Vol. 17, No. 3, pp. 335342.

[23] KORKUT, I., DONERTAS, M.A. (2007). The influence of feed rate and cutting speed on the cutting forces, surface roughness and tool-chip contact length during face milling. In: Materials \& Design, Vol. 28, pp. 308-312.

[24] KARPUSCHEWSKI, B., BATT, S. (2007). Improvement of dynamic properties in milling by integrated stepped cutting, In: CIRP Annals, Vol. 56, No. 1, pp. 85-88.

[25] BORYSENKO, D., KARPUSCHEWSKI, B., WELZEL, F., KUNDRÁK, J., FELHÖ, C. (2019). Influence of cutting ratio and tool macro geometry on process characteristics and workpiece conditions in face milling, In: CIRP
Journal of Manufacturing Science and Technology, Vol. 24, pp. 1-5.

[26] RIEF, M., KARPUSCHEWSKI, B., KALHÖFER, E. (2017). Evaluation and modeling of the energy demand during machining, In: CIRP Journal of Manufacturing Science and Technology, Vol. 19, pp. 62-71.

[27] KUNDRÁK, J., KARPUSCHEWSKI, B., PÁLMAI, Z., FELHÖ, C., MAKKAI, T., BORYSENKO, D. (2021). The energetic characteristics of milling with changing crosssection in the definition of specific cutting force by FEM method, In: CIRP Journal of Manufacturing Science and Technology, Vol. 32, pp. 6169.

[28] PÁLMAI, Z. (2006). Chaotic phenomena induced by the fast plastic deformation of metals during cutting, In: Journal of Applied Mechanics, Vol. 43, pp. 240-245.

[29] SHI, H-M., WANG, J-L. (1995). A model for non-free-cutting. In: International Journal of $\mathrm{Ma}$ chine Tools \& Manufacture, Vol. 35, No. 11, pp. 1507-1522.

[30] PÁLMAI, Z., CSERNÁK, G. (2012). Effect of built-of edge-induced oscillations on chip formation during turning. In: Journal of Sound and Vibration, Vol. 332, No. 8, pp. 2057-2069. 